
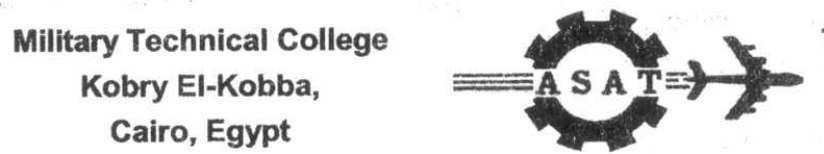

11-th International Conference

on Aerospace Sciences \&

Aviation Technology

\title{
Simulation of Satellite Heat Pipe Radiator
}

\author{
Ahmed ${ }^{*}$ Fathy, Mohamed Afify", Karam El-Shazly
}

\section{ABSTRACT}

Heat pipes are widely used in the thermal control system of satellites. A coolant fluid, being pumped through a header, collects heat from the satellite components and transfer it to the radiator heat pipes. The object of this work is to obtain relationships among the heat load of radiator, the mass flow rate of coolant fluid and the main dimensions of the radiator, in order to satisfy the temperature ranges necessary for the operation of satellite components. A mathematical model was used to simulate a heat pipe radiator. Karam's data [5] has bean used to verify the validity of the program, with header length of $8 \mathrm{~m}$, radiator height of $3.16 \mathrm{~m}$, evaporator length of $0.15 \mathrm{~m}$, number of heat pipes of 53 and satellite load of 6250 W. The output result concerning the heat transport capability of the radiator, given by the simulation program, are identical to karam's analytical results. The program was used to study the effect of some parameters like the header length, the satellite heat load and the environmental load. Changing the header length from $2 \mathrm{~m}$ to $10 \mathrm{~m}$, it has been seen that the output coolant temperature decreases as header length increases which improves the thermal control of satellite. Changing the satellite load from $3000 \mathrm{~W}$ to $10000 \mathrm{~W}$, it has been seen that the heat transport per pipe increases as the satellite thermal load increases. The results also showed that increasing the environmental load could stop the radiator function and consequently it should be insulated from the surrounding to work properly.

\section{KEY WORDS}

Satellite, Heat Pipes and Thermal Control.

\section{NOMECLATURE}

\section{Symbols}
A Cross section area $\left(\mathrm{m}^{2}\right)$
$A^{\text {a }} \quad$ Absorbed energy area $\left(\mathrm{m}^{2}\right)$
$A^{c} \quad$ Convection surface area $\left(\mathrm{m}^{2}\right)$

\footnotetext{
* Graduate student, Dpt. Of Mech. Power, Military Technical College, Cairo, Egypt.

** Lecturer, Dpt. Of Mech. Power, Military Technical College, Cairo, Egypt.

*** Professor, Dpt. Of Mech. Power, Shoubra Faculty of Engineering-Zagazig University, Cairo, Egypt.
} 


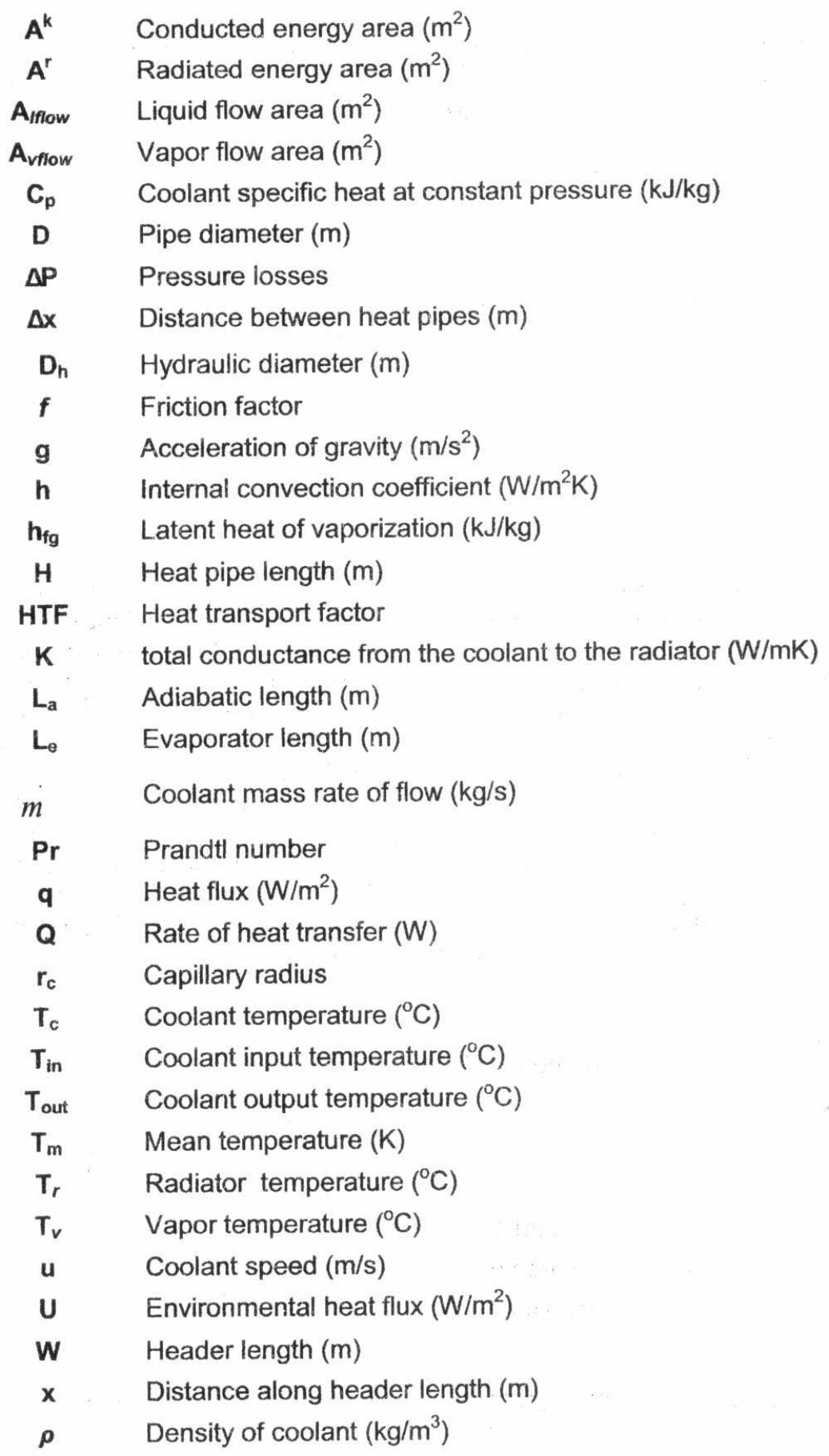




\section{Introduction}

Generally, the interior workings of a heat pipe, including startups and other transients, are a separate study and do not enter into thermal modeling. Nodal networks for satellite panels with heat pipes often represent the vapor in each pipe as an isothermal arithmetic node or a set of such nodes connected by very high conductance. The network conductors then trace the heat paths along the electronics mounting platform, across heat pipe bond lines or clamped surfaces, along flanges, tube wall, and grooves, across the wetted surface, into the vapor (evaporation); and out (condensation) to the cooling medium. The analysis assumes that the heat pipe is capable of transporting the heat loads involved and that it is functioning as intended. If required, failures and reduced performance can be simulated by removing the vapor as an active node or by modeling only part of the length as a working heat pipe.

Because of uncertainties in the uniformity of bond lines and groove structure and in the value of the convection coefficient of a two-phase fluid flow, tests are often performed on the actual hardware to obtain conductance data to be used in the analysis. Usually, the tested value is an average of several measurements made at different heat loads and temperatures.

Future satellites, with electrical power in the kilowatts range, are envisioned carrying large, deployable radiators with intricate fluid networks for distributing and rejecting waste heat. $A$ number of ideas in promoting such systems have been advanced, [1, 2, 3, 4] all proposing heat pipes and other devices that profit from phase change heat transfer and capillary pumping. One of the greater challenges in this effort has been the mechanical design of stowable systems with flexible joints and interfaces that sustain continuity of heat and fluid flow after deployment. Some of the principles and limitations associated with these concepts may be revealed by considering the heat pipe radiator coolant system schematically shown in fig. 1 . The sketches show a coolant fluid being continuously pumped through a header as it collects heat from a satellite and transfer it to the radiator heat pipes. The object is to obtain relationships among flow and geometric parameters as a basis for sizing the radiator to satisfy a temperature specification at a given heat load and allowable pressure.

\section{Mathematical Thermal Model}

The header design and the method of interfacing with the satellite and radiator are a separate study, which takes into account such factors as available space, compatibility of coolant with wall material, pumping requirements, and the system's pressure and temperature. Also, in addition to be consistent with the available pressure head and rate of heat removal, the sizing of the conduit must result in an adequate arithmetic product of the convection heat transfer coefficient and the associated area that will yield the desired temperatures. It should be noted that the conduit diameter cannot be made too large because of weight and space restrictions and because heat transfer suffers as circumferential temperature gradients increase with diameter. 
In performing the analysis, steady-state conditions and normal heat pipe operation are assumed, with the saddle region acting as evaporator and the remainder of the pipe as condenser. Both surfaces of the radiator are considered to have the same temperature profile, which is actually the case when the radiator has uniform optical properties and identical heating on both sides, and is nearly always true for thin panels. Also, as is often the approach in this type of analysis, the region defined by $\Delta \mathrm{x}$ in fig. 1. is chosen sufficiently large to encompass at least one whole saddle, but small enough so that a formulation in differential calculus is possible. This technique is exact when saddles are negligibly small, and inaccuracies increase progressively as saddle lengths grow.

Tracing the path of energy packet $\Delta Q$ from the coolant $c$ to the radiator $r$, across the interface enclosed by $\Delta \mathrm{x}$

$$
\Delta Q=-\left(\dot{m} C_{p}\right) \Delta T_{c}=K\left(T_{c}-T_{r}\right) \Delta x
$$

where: $m$ is coolant mass flow rate,

$\mathrm{C}_{\mathrm{p}}$ coolant specific heat at constant pressure,

K (W/K meter of header length) total conductance from the coolant to the radiator.

In differential form

$$
\frac{d T_{c}}{d x}=-\left[\frac{K}{\left(\dot{m} c_{p}\right)}\right]\left(T_{c}-T_{r}\right)
$$

The pervious two equations are firstly needed to calculate the coolant and radiator temperatures. The boundary condition is contained in the heat balance, which equates the total heat to be rejected $Q$ to that released by the fluid as its temperature drops from $T_{\text {in }}$ to $T_{\text {out }}$ along the header length, that is,

$$
Q=\int_{0}^{W} d Q=m c_{p}\left(T_{\text {in }}-T_{\text {out }}\right)
$$

Now, each heat pipe is nearly isothermal throughout its length and, on neglecting edge effects, the isotherms in the radiator become parallel to the heat pipes. Hence, for uniform radiator cross section and no transverse gradients, the lateral temperature distribution is one dimensional and is described by

$$
\frac{d^{2} T_{r}}{d x^{2}}+\frac{A^{a} q^{a}(x)}{K A^{k} W}-\frac{\varepsilon A^{r} \sigma T_{r}^{4}}{K A^{k} W}=0
$$

where: $W$ header length

$a, k$, and $r$ referred to absorbed, conducted and radiated respectively.

Assumption is made that lateral conduction in the radiator is insignificant and therefore, the heat released by each heat pipe is radiated mostly in its own immediate vicinity. 
This is not a radical departure from actual conditions in honeycomb panels that are lightweight and constructed in separate sections hinged together along lines of large thermal resistance. Accordingly, the differential equation is replaced by:

$$
K\left(T_{c}-T_{r}\right)+A^{a} q^{a}(x) / W=\varepsilon A^{r} \sigma T_{r}^{4} / W
$$

This is the second equation that will allow solving for $T_{c}$ and $T_{r}$ in terms of the heat to be rejected and the system's flow and geometric parameters. Solutions in simple, compact form are found by substituting:

$$
\begin{gathered}
T_{r}^{4} \approx T_{m}^{4}+4 T_{m}^{3}\left(T_{r}-T_{m}\right) \\
\text { with } T_{m} \text { conveniently } \\
\text { defined by } \\
\sigma T_{m}^{4}=\frac{1}{\varepsilon A^{r}}\left[Q+\int_{0}^{W /} q^{a}(x) d A^{a}\right]
\end{gathered}
$$

The results for a rectangular radiator of length $W$ (along the header) and height $\mathrm{H}$ (approximately the length of heat pipe; $d A^{a}=H d x$ ), as shown in fig.2, with uniformly absorbed environment flux $\mathrm{U}$ are:

$$
T_{c}=C_{1}+\left(T_{i n}+C_{1}\right) e^{\left(-C_{2} x\right)}
$$

and

$$
T_{r}=C_{3}+C_{4} T_{c}
$$

where

$$
\begin{aligned}
& C_{1}=\left(U+3 \varepsilon \sigma T_{m}^{4}\right) / 4 \varepsilon \sigma T_{m}^{3} \\
& C_{2}=\left[K / \dot{m} c_{p}\right]\left[4 \varepsilon \sigma T_{m}^{3} /\left(4 \varepsilon \sigma T_{m}^{3}+K / H\right)\right. \\
& C_{3}=\left(U+3 \varepsilon \sigma T_{m}^{4}\right) /\left(4 \varepsilon \sigma T_{m}^{3}+K / H\right) \\
& C_{4}=(K / H) /\left(4 \varepsilon \sigma T_{m}^{3}+K / H\right)
\end{aligned}
$$

and

$$
\varepsilon \sigma T_{m}^{4} \equiv[Q+U W H] / W H
$$

Emissivity $\varepsilon$ and environment flux $U$ must reflect the radiator's shape factors to space. Thus, in calculating the mean temperature, $U$ may refer to heating on one side of the radiator where as $\varepsilon$ is the sum of the emissivities if both sides are viewing space.

Total conductance $K$ from coolant fluid to radiator is calculated according to the combination rules

$$
K=1 /\left[K_{c-s}^{-1}+K_{s-h p}^{-1}+K_{h p-r}^{-1}\right]
$$

where subscripts: c coolant, 
s thermal interface between header and saddle,

hp heat pipe vapor,

$r$ radiator surface.

As required by the definition of conductance, the separate quantities must have consistent definitions in terms of geometry, which means that when $K$ is in W/K per meter of header (or radiator) length then, with no peripheral temperature variation in the header adapter:

$$
K_{c-s}=h A^{c}
$$

where: $h$ is convection coefficient

$A^{c}$ convection area.

Heat transport factor HTF (W-m), is defined by

$$
H T F \equiv \int_{0}^{L} Q(x) d x
$$

Therefore, when the geometry is consistent and fluid properties constant,

$$
H T F=\left(2 \sigma / r_{c}\right) /\left(F_{l}+F_{v}\right) \approx 2 \sigma / r_{c} F_{l}
$$

where:

$$
\begin{aligned}
& F_{l}=2\left(f_{l} \operatorname{Re}_{l}\right) \mu_{l} / D_{l}^{2} \lambda \rho_{l} A_{\text {lflow }} \\
& F_{v}=2\left(f_{v} \operatorname{Re}_{v}\right) \mu_{v} / D_{v}^{2} \lambda \rho_{v} A_{\text {vflow }}
\end{aligned}
$$

which is functionally independent of length. It also seen from the definition of $F_{1}$ that for uniform geometry and constant properties of the coolant the heat transport factor is proportional to $\sigma \lambda \rho_{l} / \mu_{l}$. This combination of liquid properties is a measure of the effectiveness of working fluid to transport heat. It is relatively high for ammonia.

The integral form used throughout is essential to establish a basis for treating situations in which heat absorption and rejection are not uniform and may occur at intermittent locations along the pipe. It is important to note, however, that for a standard heat pipe consisting of one evaporator, perhaps followed by an inactive (adiabatic) section, and one condenser, HTF can be calculated without reference to length. Hence, once obtained for a given cross section and working fluid, it will serve to judge the performance of all heat pipes of the same cross section and working fluid in terms of whether or not they can transport a particular heat load along a given length. HTF can be used as a baseline for comparing the performance of heat pipes of different lengths.

Maximum capillary pressure was incorporated in the analysis to find the maximum possible heat transport $Q_{\max }$ within capillary limitations. In the oneevaporator one-condenser configuration, this is the integrated axial heat flux in the evaporator; that is,

$$
Q_{\max }=\int_{0}^{L_{e}} q(x) d x
$$

where; $L_{e}$ is the evaporator length. For uniform heating $[q(x)$ is constant], axial heat flow can be put in terms of maximum heat transport as follows: 


$$
\begin{array}{ll}
Q(x)=\left(Q_{\max } / L_{e}\right) x & \text { for } 0 \leq x \leq L_{e} \\
Q(x)=Q_{\max } & \text { for } L_{e} \leq x \leq\left(L_{e}+L_{a}\right) \\
Q(x)=\left(Q_{\max } / L_{c}\right)(L-x) & \text { for }\left(L_{e}+L_{a}\right) \leq x \leq L
\end{array}
$$

where; $L_{c}$ and $L_{a}$ are the lengths of the condenser and adiabatic sections. Hence, maximum heat transport factor $H T F_{\max }$ is

$$
\begin{array}{r}
H T F_{\max }=\int_{0}^{L} Q(x) d x=\int_{0}^{L_{e}} \frac{Q_{\max }}{L_{e}} x d x \\
+\int_{L_{e}}^{L_{e}+L_{a}} Q_{\max } d x+\int_{L_{c}+L_{a}}^{L} \frac{Q_{\max }}{L_{c}}(L-x) d x \\
=\left(0.5 L_{e}+L_{a}+0.5 L_{c}\right) Q_{\max }
\end{array}
$$

This equation contains a constraint, dictated by $H T F_{\max }$ on the manner of distribution of maximum heat load along a heat pipe of a given length. Requirements on both $Q_{\max }$ and $H T F_{\max }$ are usually given in the heat pipe specifications. Note that when a heat pipe consists of just an evaporator and a condenser, without an adiabatic section,

$$
H T F_{\max }=Q_{\max } L / 2
$$

where $L$ Heat pipe length 

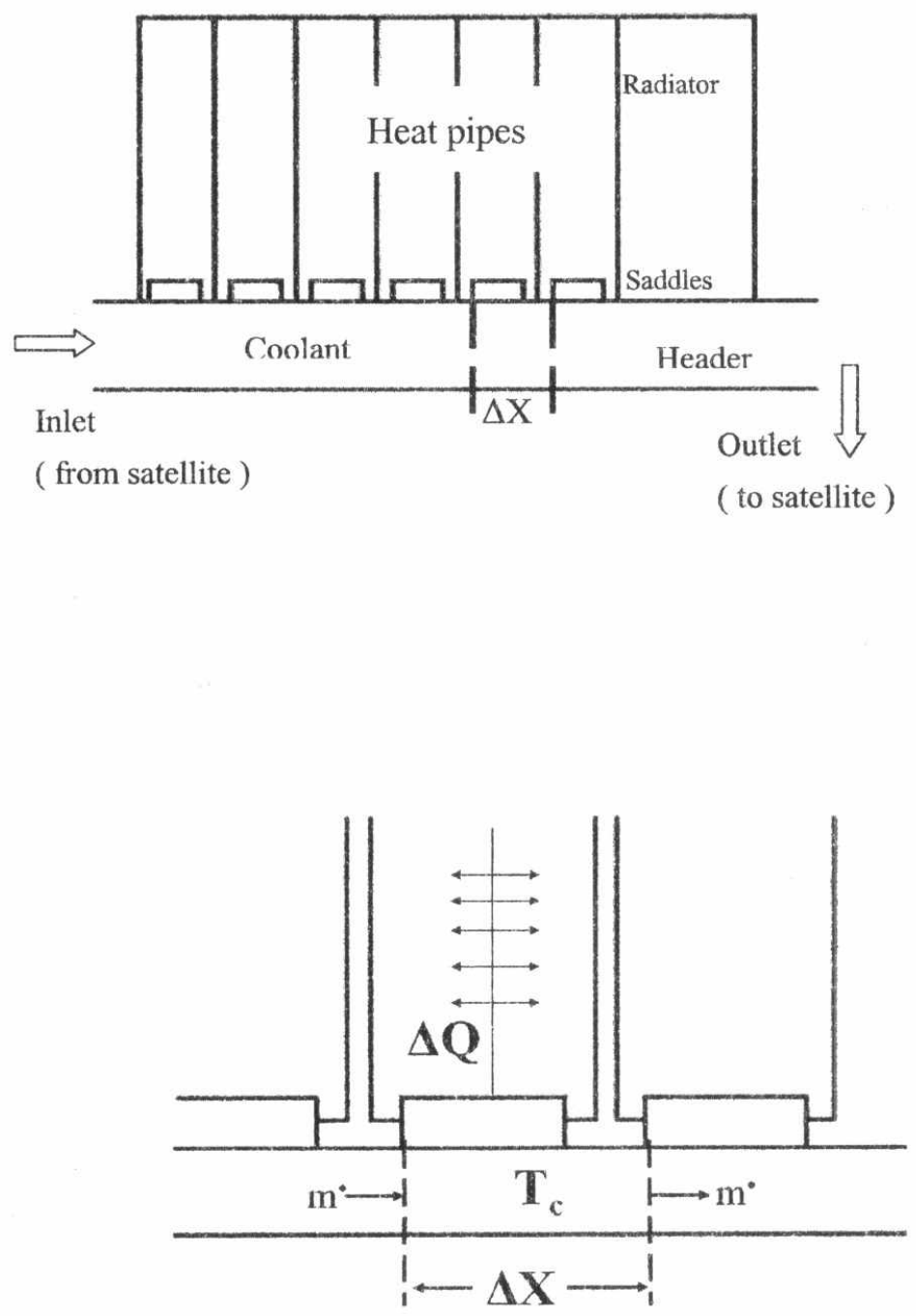

Fig.1. Heat pipe radiator coolant system 

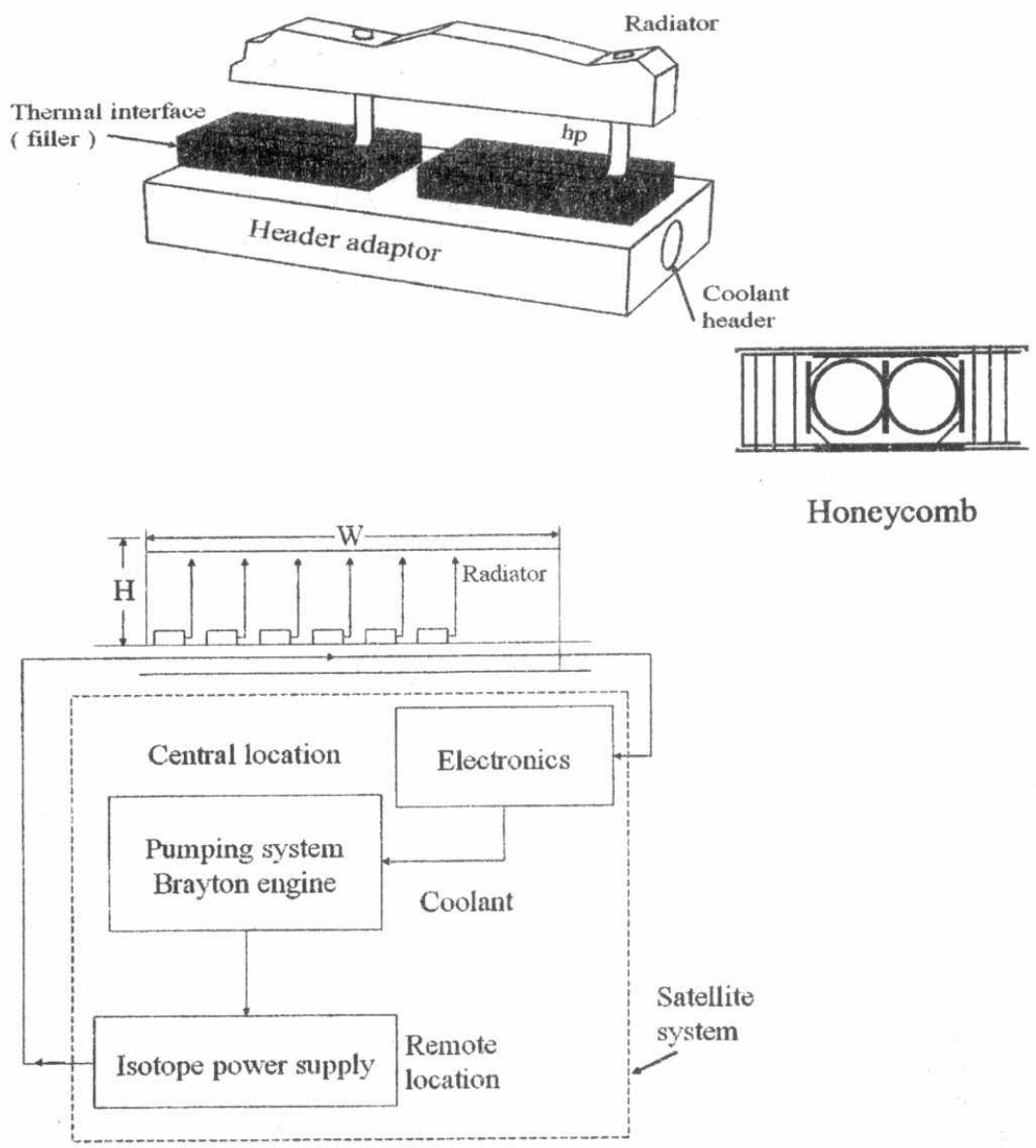

Honeycomb

Fig.2. Satellite thermal control by circulating coolant with heat rejection to heat pipe radiator 


\section{Simulation Program}

In the present work Matlab (Fig.3.) is used to make simulation program for satellites radiator using the previous mathematical model.

$K_{s-h p}$ and $K_{h p-r}$ have values for the particular saddled heat pipe configuration but must be modified to indicate the interface geometry along header length. For the configuration and data from NASA (Tests on AST6 heat pipes in honeycomb panels [5]), an isothermal saddle of length $15 \mathrm{~cm}$ along the header yields

$$
K_{s-h p}=K_{b l-v}(100 / 15) \quad \text { W/K per meter of header length }
$$

and according to the case of a heat pipe partially saddled, $K_{b l-v}=9.0 \mathrm{~W} / \mathrm{K}$ over contact area [21].Also,

$$
K_{h p-r}=2 K_{f s-v}(100 / 15) H \quad \text { W/K per meter of header length }
$$

where ; $H$ is the heat pipe length

$$
K_{f s-v}=20.4 \quad W / K \text { per meter of heat pipe length over contact area }
$$

The factor 2 on the right hand side comes from the assumption that the heat pipe is coupled equally to both face sheets of the honeycomb radiator. Therefore,

$$
K=1 /\left[1 / h A^{c}+1 / 60+1 / 272 H\right]
$$

Using Karam [40] analytical model to verify present program, which take header length $(W)$ of $8 \mathrm{~m}$, Radiator height $(H)$ of $3.16 \mathrm{~m}$, evaporator length $\left(L_{e}=0.15\right.$ $\mathrm{m}$ ), satellite load of $6250 \mathrm{~W}$ and number of heat pipes of 53. Fig.2. shows the application of heat pipe radiator in cooling of nuclear powered communication satellite, in which the circulating working fluid (helium/xenon mixture) of the radioisotope thermodynamic cycle is used for the thermal control of shelf on which standard electronics are mounted. The satellite is in GEO, and precision pointing maintains the radiator nearly free of solar impingement. The coolant known to leave the nuclear source at $100{ }^{\circ} \mathrm{C}$, and it is required that the electronics mounting platform be maintained between 0 and $40{ }^{\circ} \mathrm{C}$. The operating pressure is $2.62 \times 10^{5} \mathrm{~N} / \mathrm{m}^{2}$ and pressure loss external to the satellite system must not exceed $25 \%$ of that value, or $6.55 \times 10^{4} \mathrm{~N} / \mathrm{m}^{2}$. The coolant rate properties as function of temperature are given in table1. , while table 2. gives the temperature range of typical satellites' component [6].

The output results from the simulation program by using of Karam's parameters is identical to Karam's analytical results as shown in Figures 4 and 5 
Table 1. Properties of He/Xe mixture [5]

\begin{tabular}{|c|c|c|c|c|c|}
\hline $\mathrm{T}\left({ }^{\circ} \mathrm{C}\right)$ & $\mathrm{c}_{\mathrm{p}}(\mathrm{J} / \mathrm{kg} \mathrm{K})$ & $\rho\left(\mathrm{kg} / \mathrm{m}^{3}\right)$ & $k_{f}(\mathrm{~W} / \mathrm{mK})$ & $\mu\left(\mathrm{Ns} / \mathrm{m}^{2}\right)$ & $\mathrm{Pr}$ \\
\hline-17.8 & 247.86 & 6.08 & 0.0216 & $2.08 \times 10^{-5}$ & 0.239 \\
\hline 40 & 247.86 & 6.08 & 0.026 & $2.57 \times 10^{-5}$ & 0.245 \\
\hline 96.1 & 247.86 & 6.08 & 0.0299 & $2.98 \times 10^{-5}$ & 0247 \\
\hline 200 & 244.22 & 5.92 & 0.0353 & $3.67 \times 10^{-5}$ & 0.254 \\
\hline
\end{tabular}

Table 2. Temperature range of typical satellites components [6]

\begin{tabular}{|l|l|}
\hline Electronic equipment (operating) & -10 to $+40{ }^{\circ} \mathrm{C}$ \\
\hline Batteries & -5 to $+15^{\circ} \mathrm{C}$ \\
\hline Fuel (e.g. hydrazine) & +9 to $+40{ }^{\circ} \mathrm{C}$ \\
\hline Microprocessors & -5 to $+40{ }^{\circ} \mathrm{C}$ \\
\hline Bearing mechanisms & -45 to $+65^{\circ} \mathrm{C}$ \\
\hline Solar cells & -60 to $+55^{\circ} \mathrm{C}$ \\
\hline Solid-state diodes & -60 to $+95^{\circ} \mathrm{C}$ \\
\hline
\end{tabular}




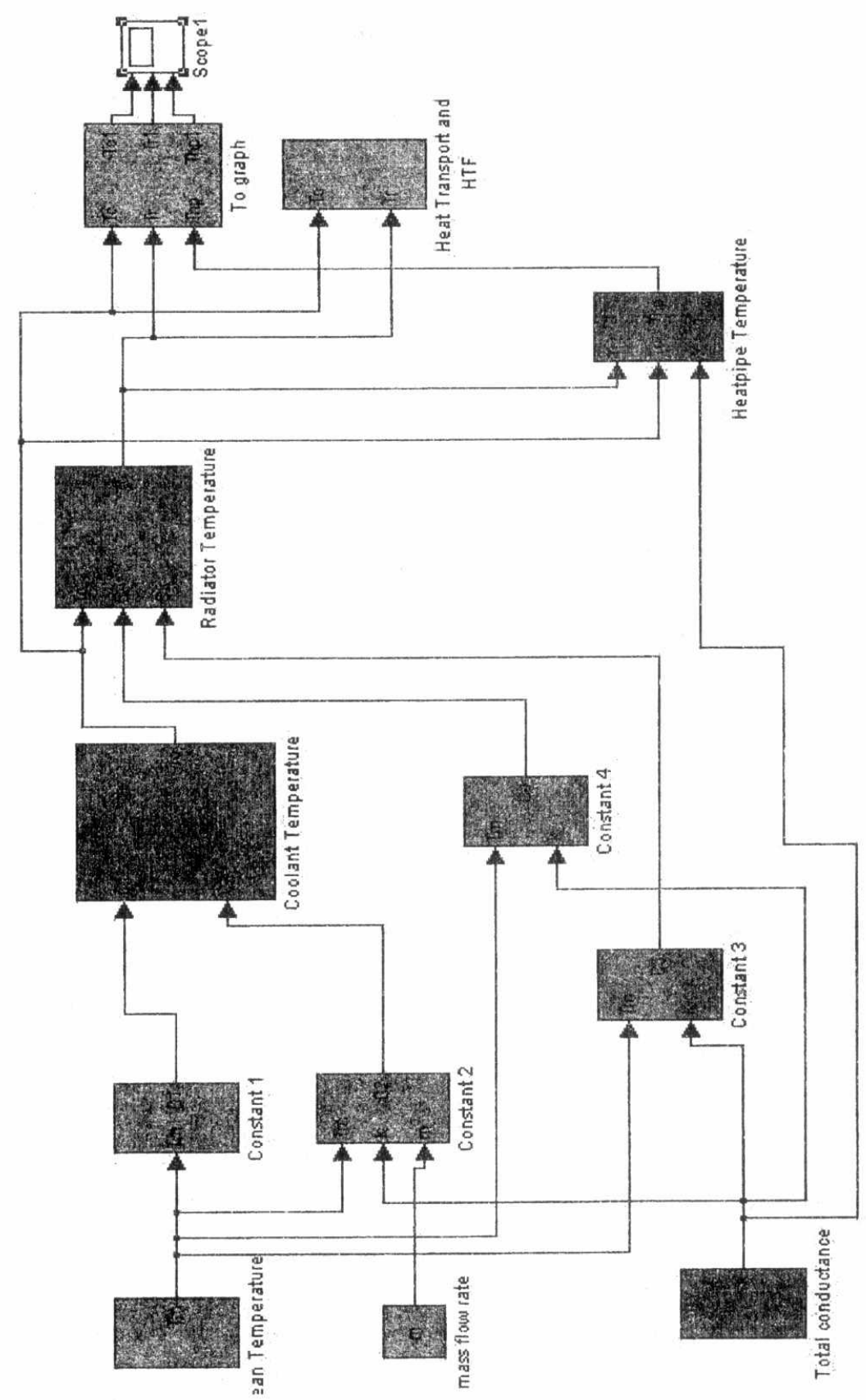

Fig.3. Block scheme for simulation program 


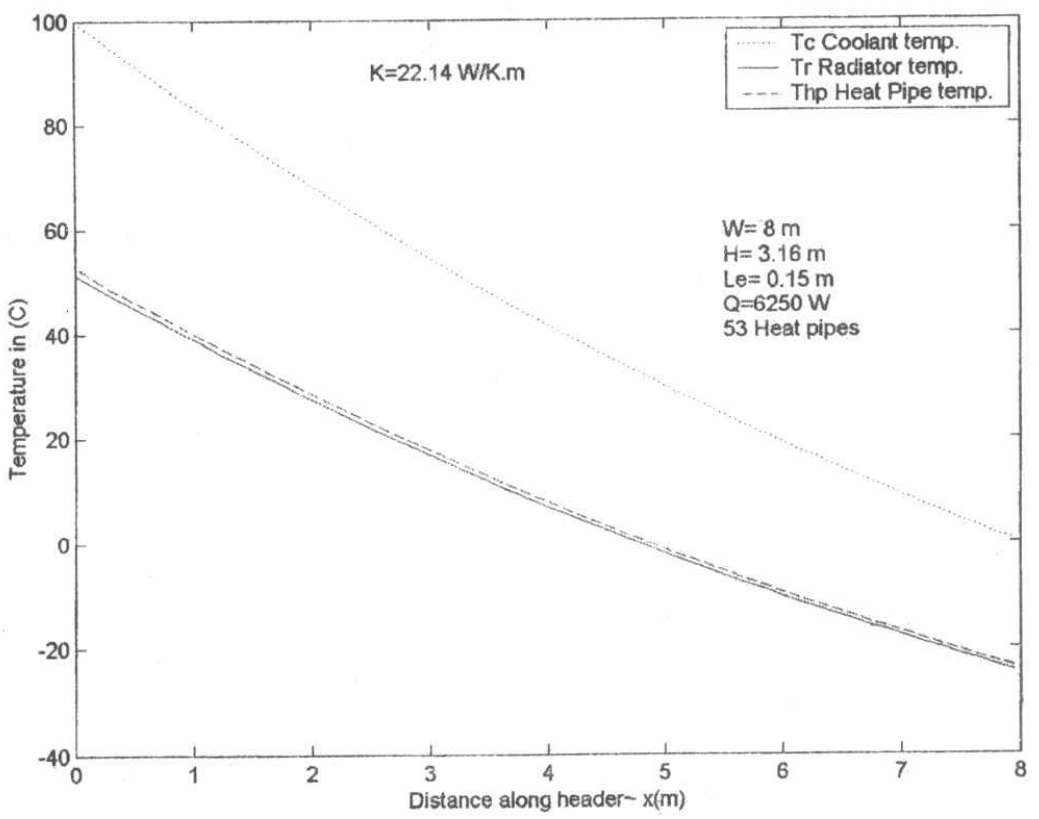

Fig.4. Karam results using the present simulation program

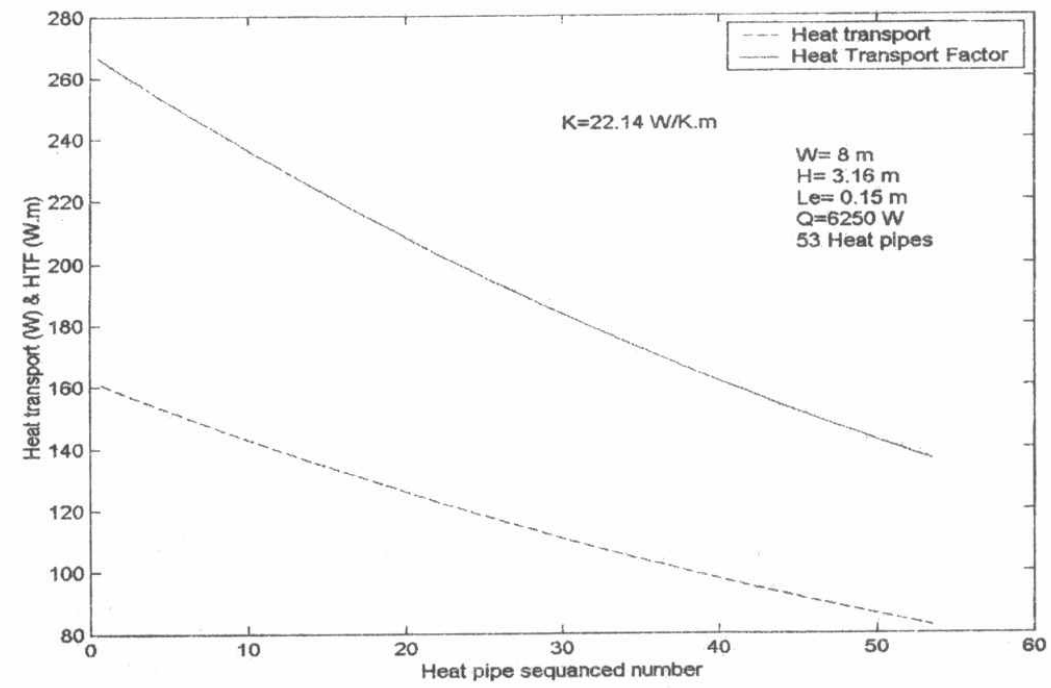

Fig.5. Karam results using the present simulation program 


\section{Analysis of the Theoretical Results}

The program is used to study the effect of some parameters like the header length, the effect of satellite thermal load and environmental heat.

Satellite thermal load is mainly due to the heat generated within the satellite, components producing heat include rocket motors, electronic devices, and batteries or any other components in the satellite.

Environmental heat is the heat transferred to the satellite from the surroundings by means of the following:

- Direct solar radiation

- Solar radiation reflected from nearby planets (albedo radiation) and

- Thermal energy radiated from nearby planets.

\section{1- Effect of header length}

To study the effect of header length, all other parameters are fixed. The heat pipe total length of $3.16 \mathrm{~m}$, evaporator section length of $0.15 \mathrm{~m}$, satellite thermal load of $6250 \mathrm{~W}$, total conductance of 22.14 (W/m.K), the same mass flow rate of the coolant and fixed distance between the heat pipes are considered.

Fig.6. shows effect of header length on the outlet coolant temperature. The outlet coolant temperature decreases as the header length increases. That is useful for thermal control of satellites under two limitations are considered: the first limit is the operating temperature range of the satellites devices as shown in table 2., the second limit is the pressure drop along the header $\Delta P_{\max }$

To calculating the allowable header length we use the following equation.

\begin{tabular}{|c|c|}
\hline & $W_{\max }=\frac{\Delta P_{\max }}{(\Delta P / W)}$ \\
\hline \multicolumn{2}{|l|}{ Where } \\
\hline W & header length \\
\hline \multirow[t]{2}{*}{$\Delta P_{\max }$} & pressure losses ( not exceed $25 \%$ ) \\
\hline & $\Delta P / W=2 f \rho u^{2} / D_{h}$ \\
\hline \multicolumn{2}{|l|}{ Where } \\
\hline$f$ & friction factor \\
\hline $\mathrm{u}$ & coolant speed \\
\hline$D_{h}$ & hydraulic diameter \\
\hline$\rho$ & Coolant density \\
\hline
\end{tabular}

Fig.7. shows the effect of header length on the radiator temperature. The temperature of the radiator increases as the header length increases and that is because the satellite thermal load is the same for each header length. So when the header length increases the area of radiator increases then the temperature gradient between coolant and radiator decreases hence the mean temperature of radiator increases. 
Fig.8. shows the effect of header length on heat pipe temperature. Note that the temperature of heat pipe increasing as the header length increases. This is because the heat load of satellite is the same at each header length but the number of heat pipe increasing. So the heat to be transferred by each one decreases as the temperature gradient decreases and that mean the temperature of heat pipe increases.

Figures (9-10) show the effect of header length on the heat transport and the heat transport factor. The heat transport from each heat pipe decreases as the header length increases and that is because the satellite heat load is the same.

As shown in figures (6-10), care should be taken during heat pipe selection, because the heat capacity of the pipe depends on the header length and the number of heat pipes ( as the number of heat pipes increase, the heat capacity of each heat pipe decrease so the cost decrease).

According to their capacity, heat pipes may be arranged in the header to satisfy the coolant temperature distribution along the header length.

Behavior of heat transport and heat transport factor is similar as indicated from equation (16).

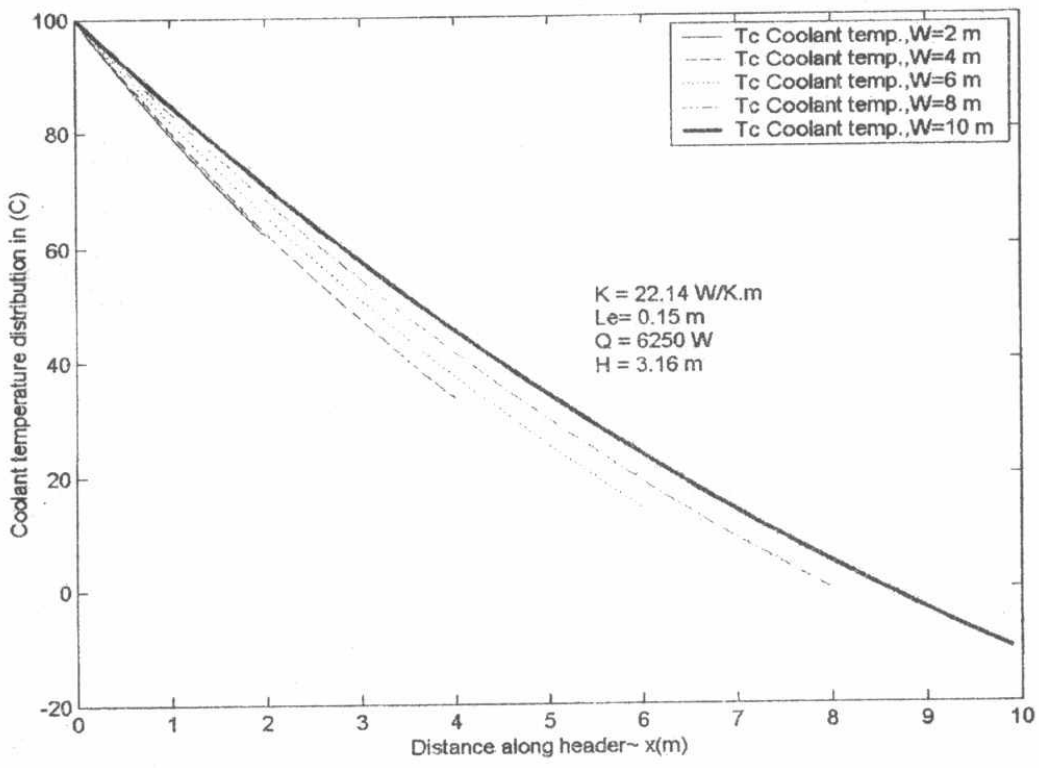

Fig.6. Effect of header length on the coolant temperatures distribution 


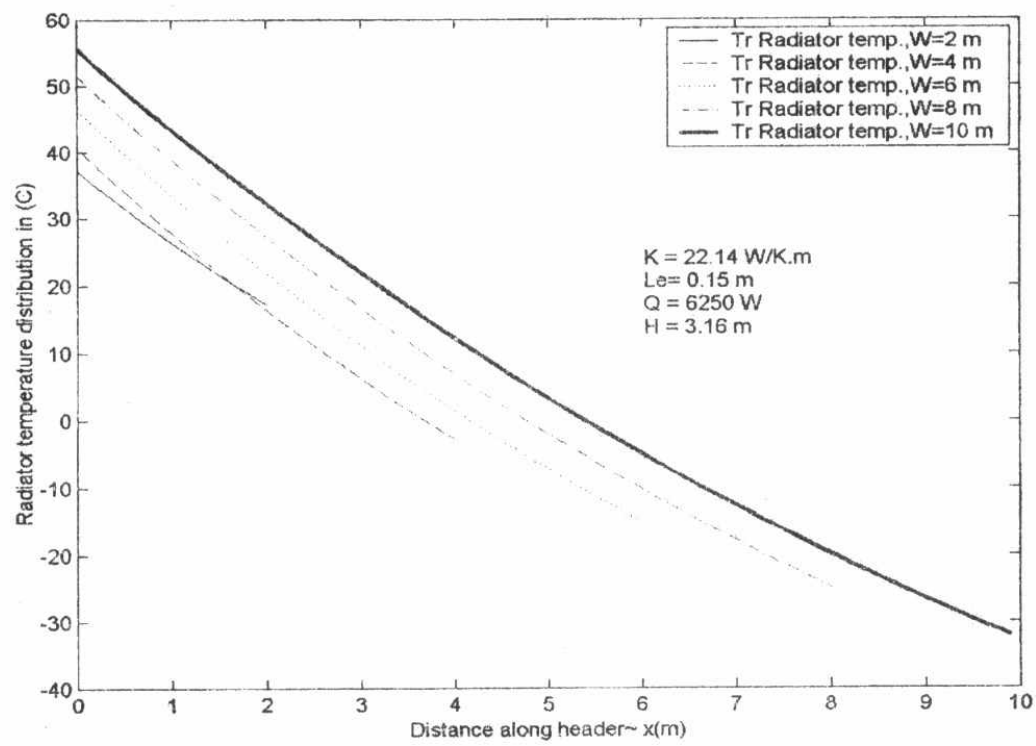

Fig.7. Effect of header length on the radiator temperatures distribution

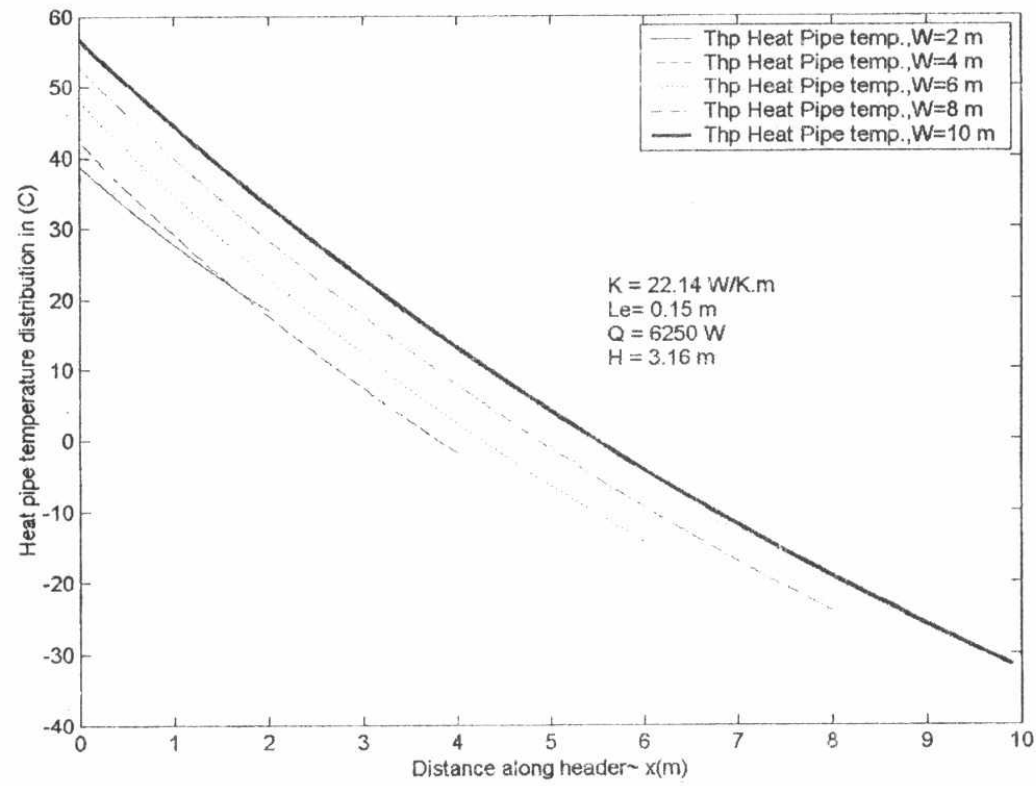

Fig.8. Effect of header length on the heat pipe temperatures distribution 


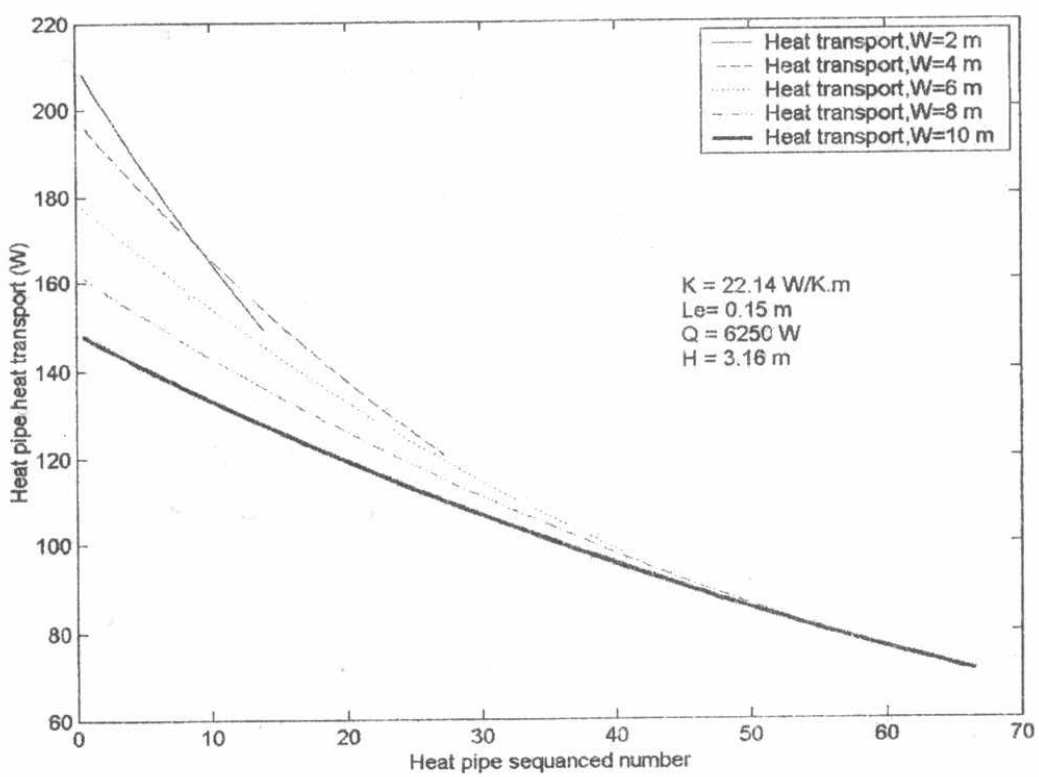

Fig.9. Effect of header length on heat pipe heat transport

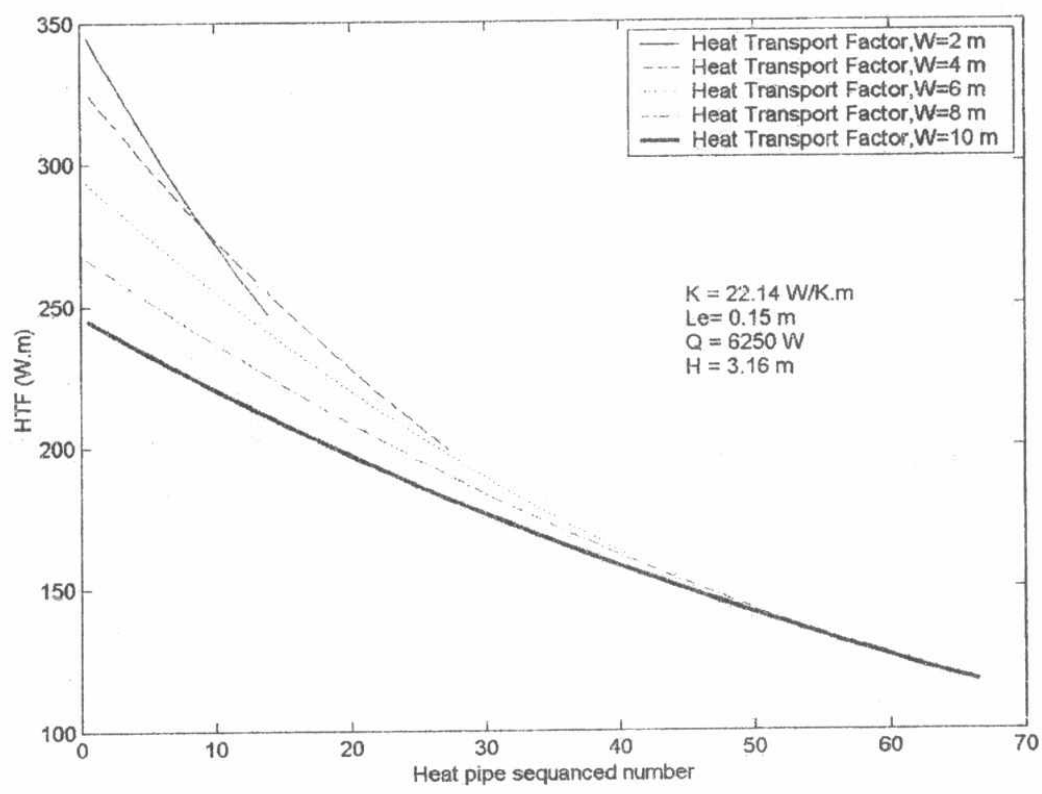

Fig.10. Effect of header length on the heat transport factor 


\section{2- Effect of increase satellite thermal load}

To study the effect of satellite thermal load, all other parameters are fixed: the heat pipe length of $3.16 \mathrm{~m}$, evaporator section length of $0.15 \mathrm{~m}$, header length of $8 \mathrm{~m}$ and total conductance equal $22.14(\mathrm{~W} / \mathrm{m} . \mathrm{K})$, also the same mass flow rate of coolant and number of heat pipes (53 H.P.).

Using constant inlet coolant temperature the outlet coolant temperature decreases to achieve the appropriate heat transport as shown in fig. 11.

The difference between the radiator temperature and coolant temperature increase as shown in fig. 12 .

According to satisfy heat transport heat pipes temperature should be lower shown in fig.13, so we have to select heat pipes with higher capacity to achieve the heat transport of higher thermal load as shown in fig. 14 and 15 leading to lower temperature of inlet coolant to the satellite space (exit temperature from header).

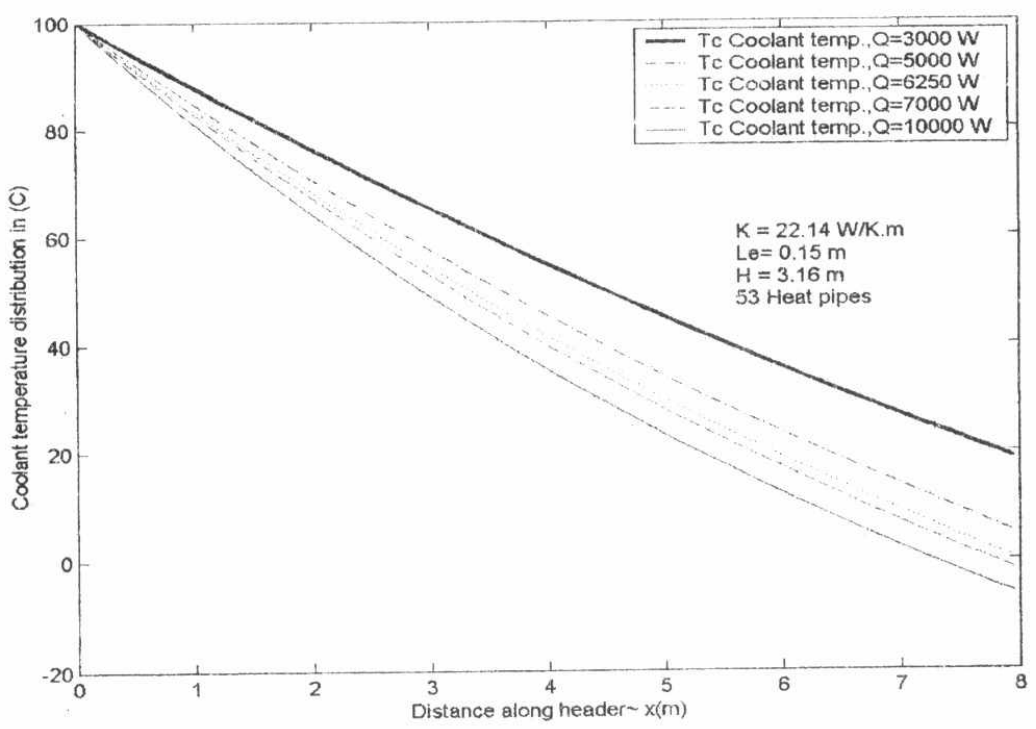

Fig.11. Effect of thermal load on the coolant temperature distribution 


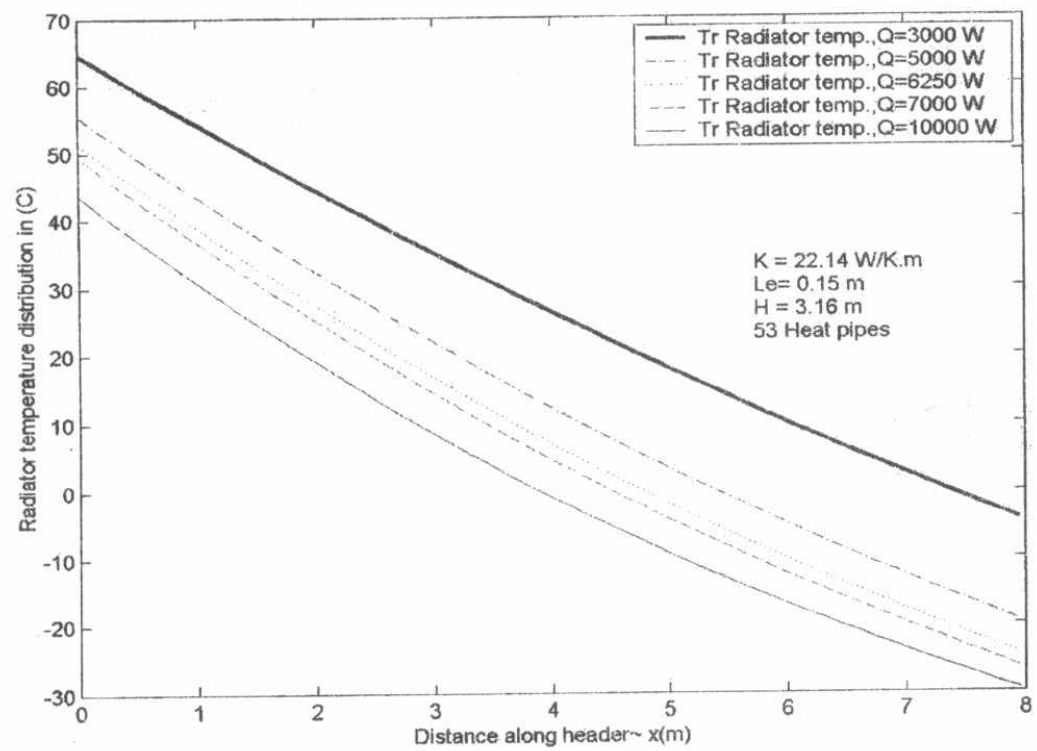

Fig.12. Effect of thermal load on the radiator temperature distribution

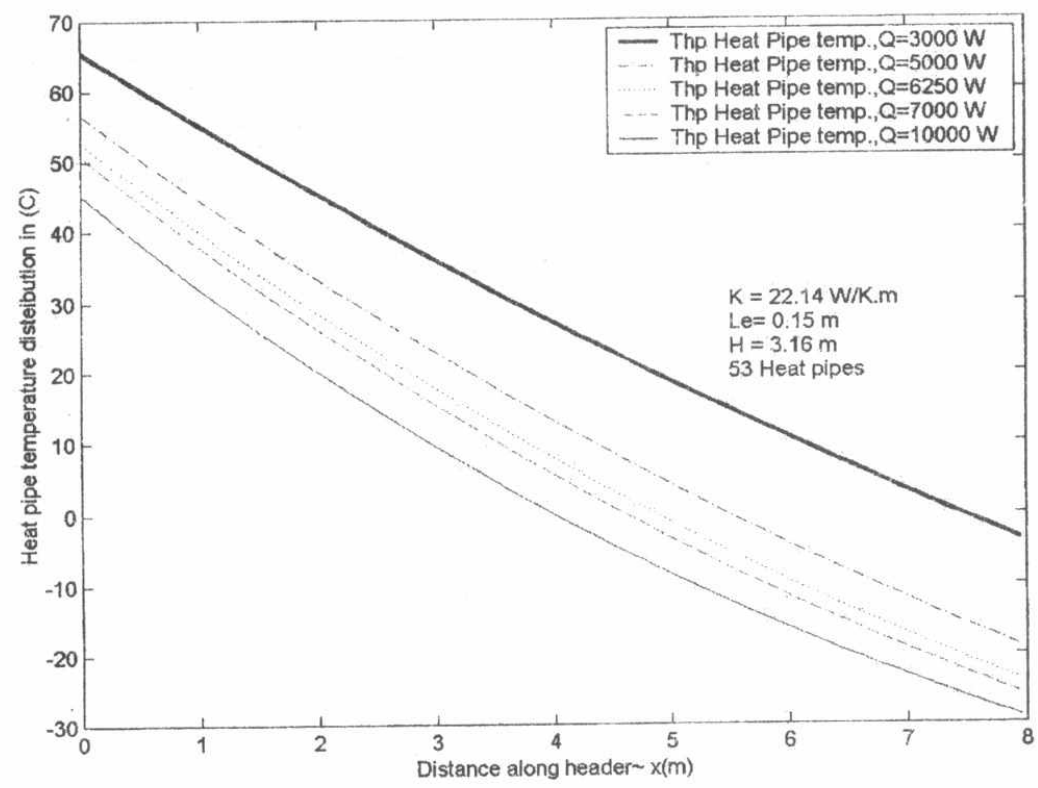

Fig.13. Effect of thermal load on the heat pipe temperatures distribution 


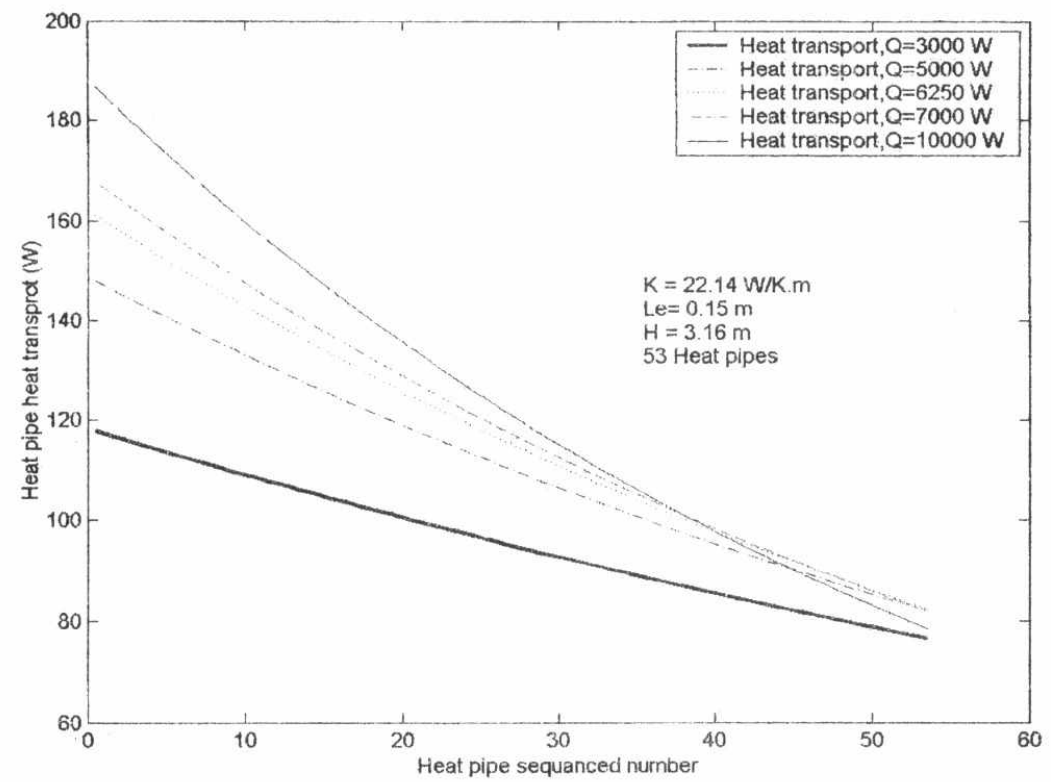

Fig.14. Effect of thermal load on heat pipe heat transport

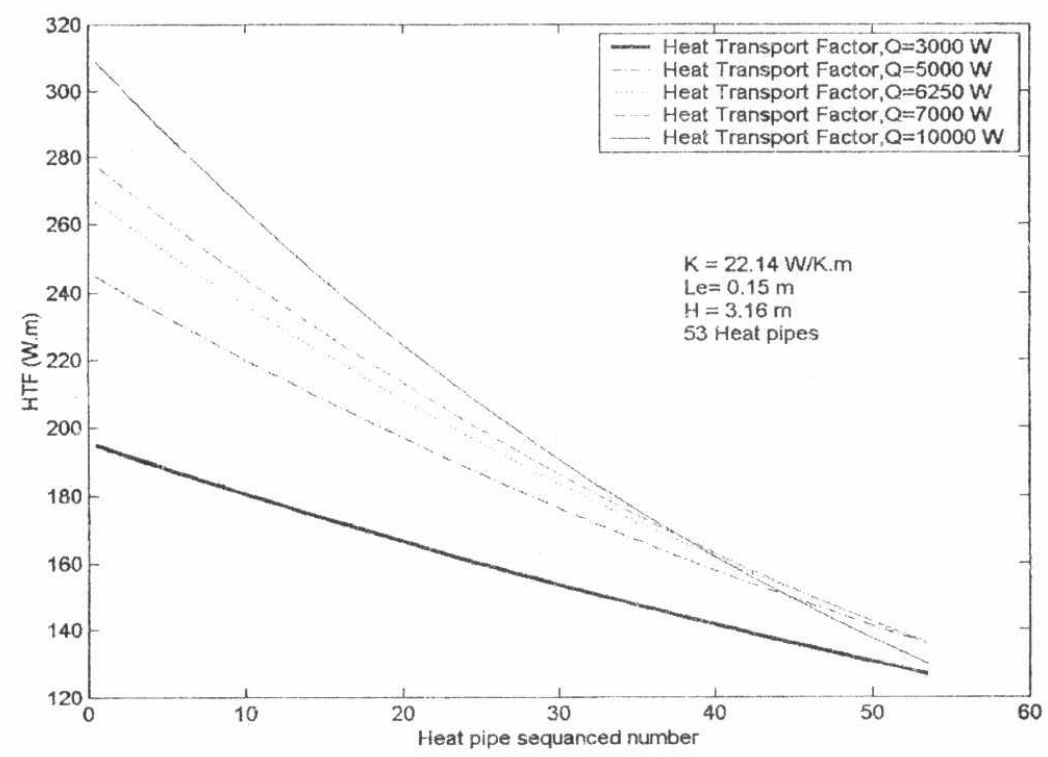

Fig.15. Effect of heat load on the heat transport factor 


\section{3- Effect of environmental heat}

The increasing of environmental heat could stop the radiator work and may transfer heat to satellite space as shown in figures (16-20).

To avoid this phenomenon, we have to insulate the radiator from the surroundings, this could be done by using housing cover coupled with louvers controlled by actuators that closed and opened according to the amount of radiation fall on them.

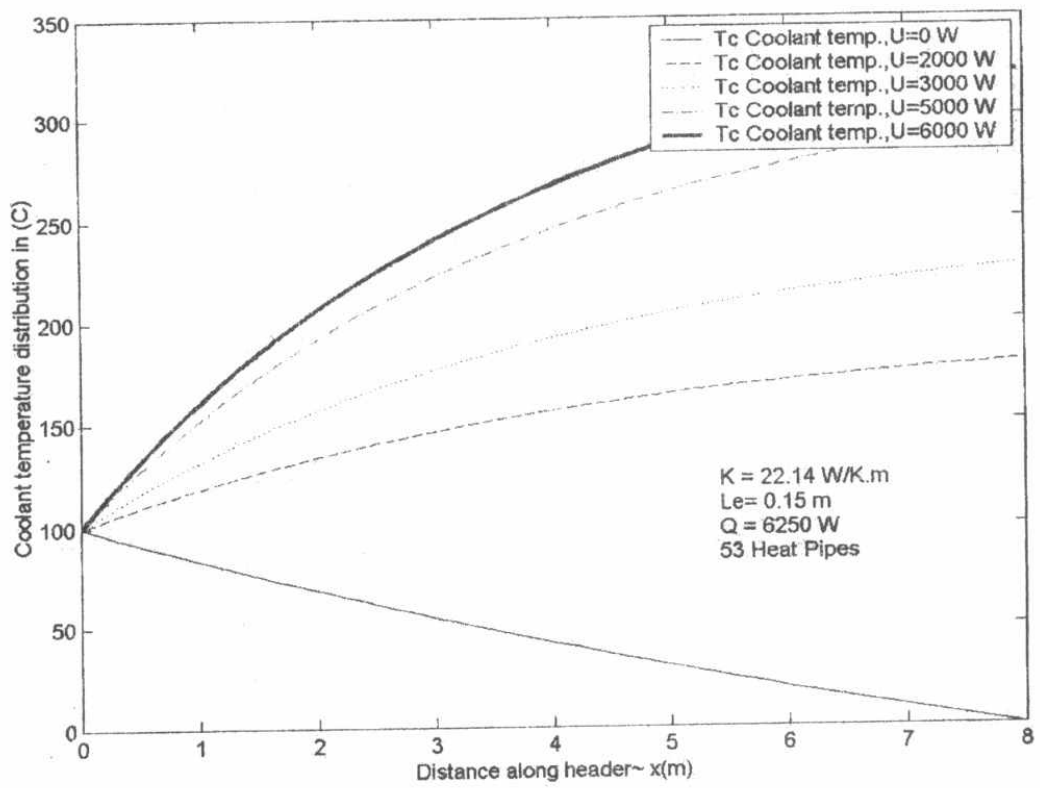

Fig.16. Effect of environmental heat on the coolant temperature 


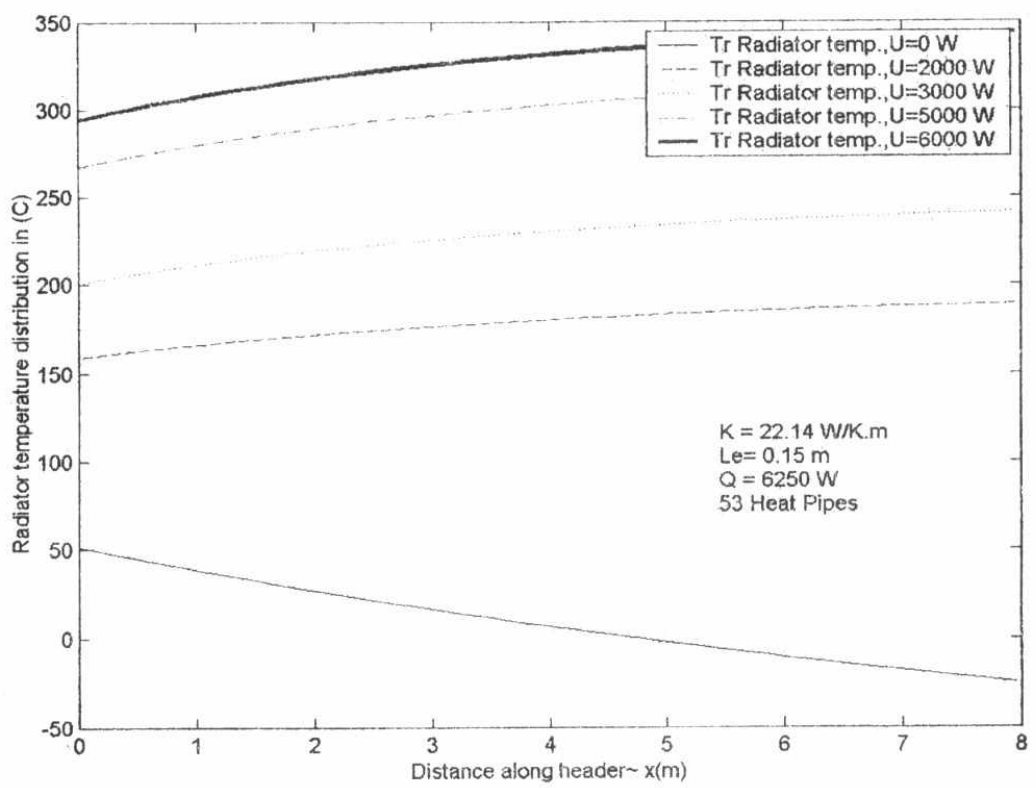

Fig.17. Effect of environmental heat on the radiator temperature

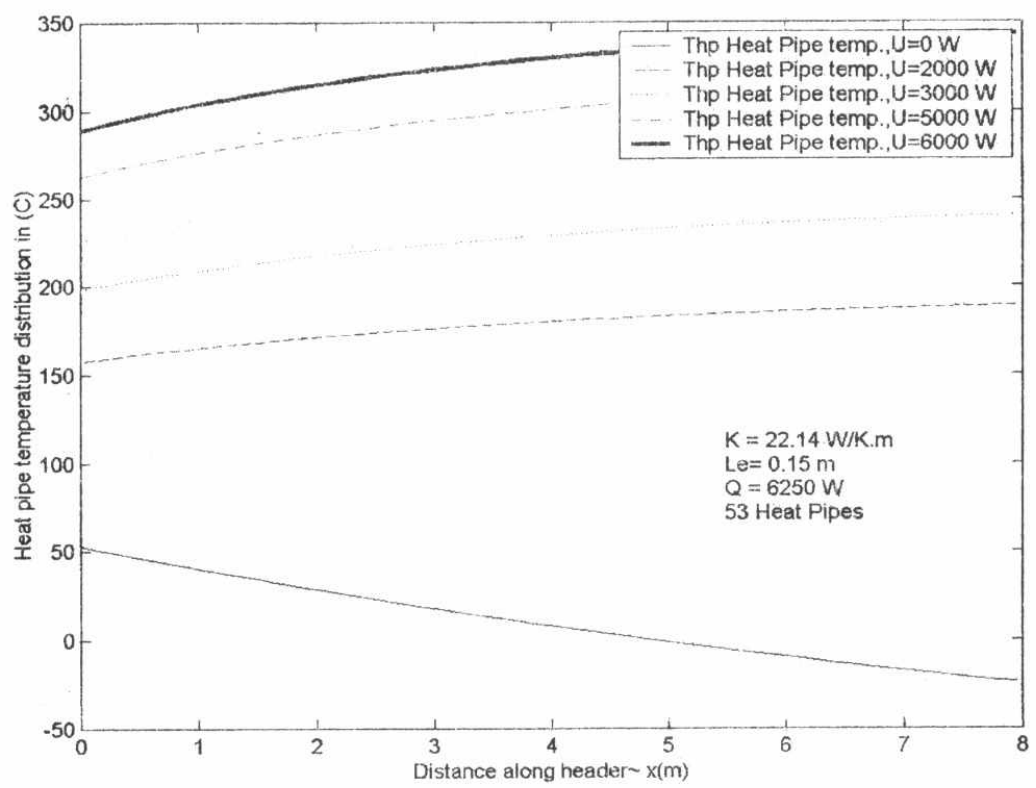

Fig.18. Effect of environmental heat on the heat pipe temperature 


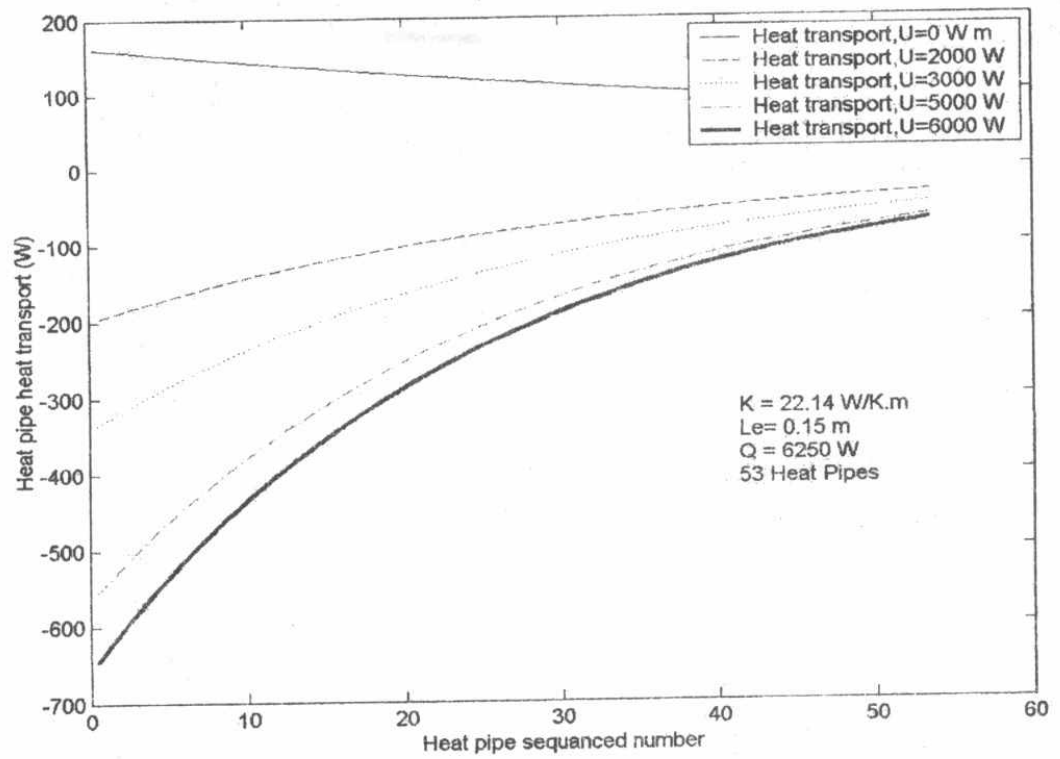

Fig.19. Effect of environmental heat on the heat pipe heat transport

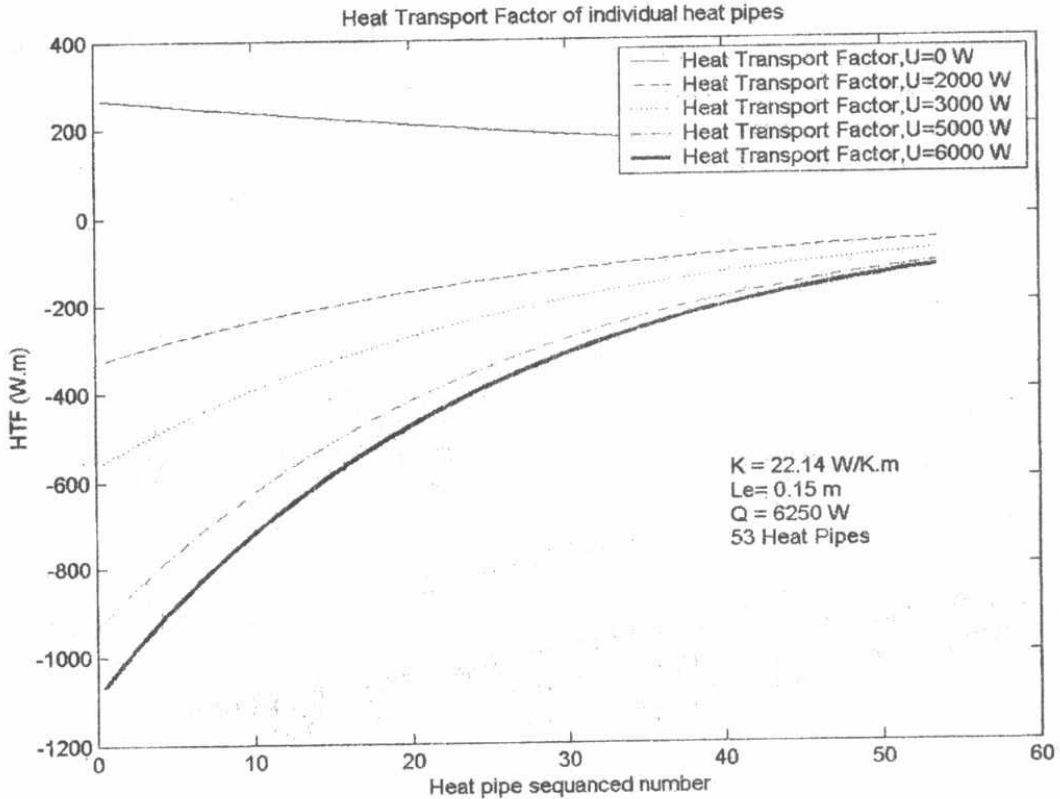

Fig.20. Effect of environmental heat on the heat transport factor 


\section{Conclusions}

Mathematical model is used to make simulation program for satellite radiator using heat pipes, the results showed that:

1- Increasing the header length may lead to the decrease of the heat pipes capacity and that would decrease the cost of heat pipe needed and that is governed by the pressure losses along header length.

2- Increasing the heat load of satellite the coolant temperature may increase. To decrease coolant temperature there are two ways: increasing the mass flow rate of coolant or, increasing the heat capacity of heat pipe (the satellite radiator should be designed to work on the maximum heat load).

3- Increasing of environmental heat could stop the radiator work and may transfer heat to satellite space. so the radiator should be insulated from surrounding to work properly.

\section{References}

[1] D. Butler and T. Hoang, The Enhanced Capillary Pumped Loop Flight Experiment: A Prototype of EOS Platform Thermal control System, AIAA Paper 91-1377, 1991.

[2] H. Masumoto, Development of a VCHP/FCHP Radiator System for 3-Axis Stabilized Geostationary Satellite Application, AIAA Paper 851012, 1985.

[3] J. Feig , Radiator Concepts for High Power System in Space , AIAA Paper 84-0055 1984.

[4] R. D. Karam and H. Hwangbo, Thermal Interaction between a Heat Pipe Radiator and a Coolant Fluid Header, Advances in Heat Pipe Technology: Proceedings of Fourth international Heat Pipe Conference, edited by D. A. Reay, Pergamon, Oxford, England, UK, pp.493-503,1981.

[5] Robert D. Karam, Book of "Satellite Thermal Control for Systems Engineers ", July 1998.

[6] Ross A. Henderson, Thermal Control of Spacecraft, Spacecraft Systems Engineering (Second Edition). Edited by P. W. Portescue and J. P. W. Stark@ John Wiley \& Sons Ltd 1995. 